\title{
Strain-dependent and indirect effect of Stenotrophomonas maltophilia on Aspergillus fumigatus in mixed biofilm
}

Elise Melloul ${ }^{1}$, Lolita Roisin ${ }^{1}$, Paul-Louis Woerther ${ }^{1,2}$, Jacques Guillot ${ }^{1,3}$, Jean-Winoc Decousser ${ }^{1,2}$, Francoise Botterel ${ }^{1,2}$

Aspergillus fumigatus (Af) and Stenotrophomonas maltophilia (Sm) colonize the respiratory tract of immunocompromised patients or with chronic pulmonary diseases and form biofilms. We recently discovered an antibiosis effect of Sm on Af in an in vitro mixed biofilm realised at $37^{\circ} \mathrm{C}$ in RPMI + FBS medium. The bacteria inhibited the fungal growth and induced an increase of fungal cell wall thickness, which led to abnormal mycelium with highly branched hyphae. Our last study showed that all the Af strains were susceptible to Sm effects.

\section{Is the fungal phenotype and inhibition in mixed biofilm dependent of Sm strains?}

\section{Methods}

Planktonic culture of Sm strains: $24 \mathrm{~h}$ in LB medium at 25 or $37^{\circ} \mathrm{C}$ with agitation $(200$ rpm). Bacterial growth assessed by spectrophotometry (600 nm).

Formation of biofilms: polystyrene supports, in RPMI + FBS medium at 25 or $37^{\circ} \mathrm{C}$ for $24 \mathrm{~h}$, without agitation

$\rightarrow$ Single inoculation of Sm strains $\left(10^{6}\right.$ cells $\left./ \mathrm{mL}\right)$. Biofilms biomass assessed by crystal violet coloration

$\rightarrow$ Co-inoculation of Af $13073-G F P$ strain at $10^{5}$ conidia/mL with different strains of Sm (Tab 1 ) at $10^{6}$ or $10^{8}$ cells $/ \mathrm{mL}$. Assessed by CLSM (biofilm thickness and Af phenotype) and qPCR (Af quantification in single and mixed biofilms)

\begin{tabular}{cllll} 
Isolates ID & Origin & & Genogroup \\
\hline Sm13637 & Human & & Mouth & 6 \\
Sm_6-1 & Human & & Sputum & 6 \\
Sm_6-2 & Human & & Catheter & 6 \\
Sm_6-3 & Animal & Dog & Trachea & 6 \\
Sm_2-1 & Animal & Horse & Trachea & 2 \\
Sm_2-2 & Animal & Horse & Trachea & 2 \\
Sm_D-1 & Hospital environment & Endoscope & D \\
Sm_D-2 & Hospital environment & Endoscope & D \\
Sm_D-3 & Hospital environment & Gastroscope & D
\end{tabular}

Tab 1: S. maltophilia strains used to form mixed biofilm with Af13073

\section{Results}

Fig 1: planktonic and biofilm culture of Sm strains at 25 or $37^{\circ} \mathrm{C}(24 \mathrm{~h})$

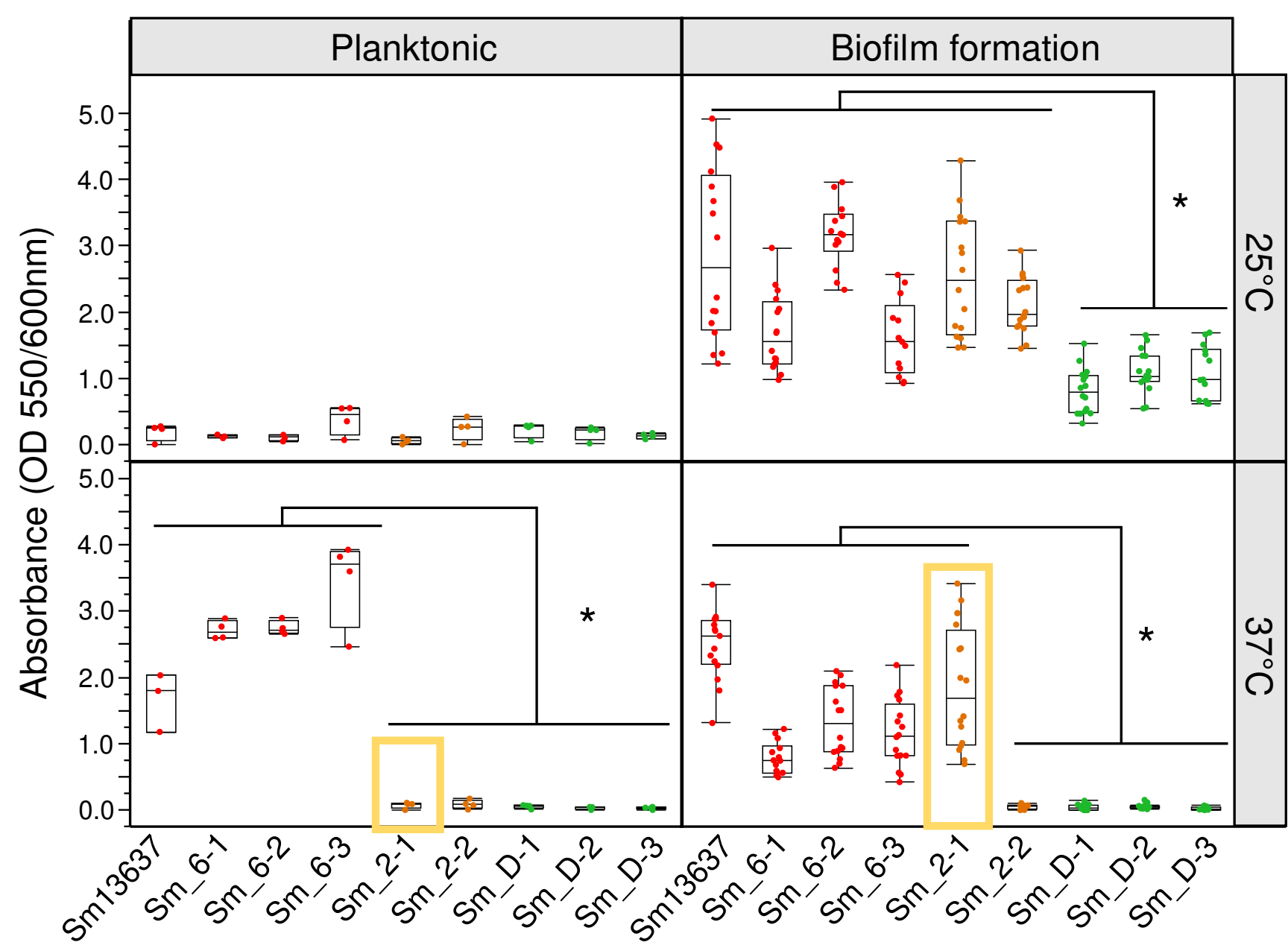

Fig 3: Quantification of Af biomass in mixed biofilms and Af phenotype

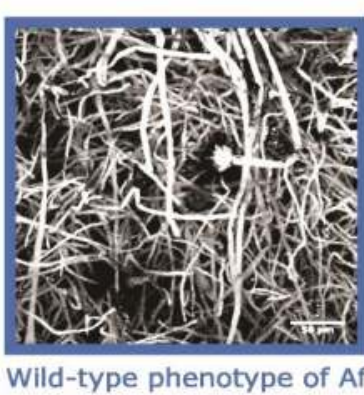
depending of Sm strains

Sm concentration in mixed biofilm = $10^{6}$ bacteria $/ \mathrm{mL}$

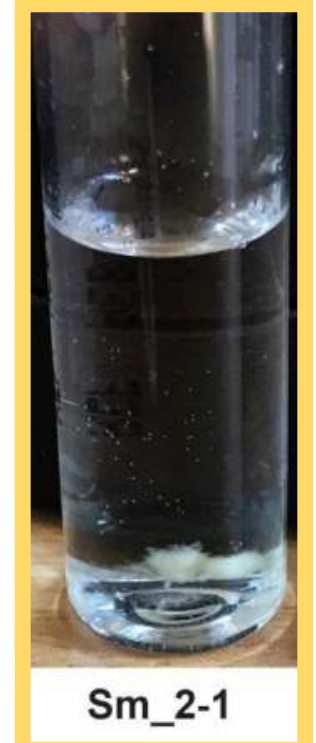

Floculation of Sm 2-1 strain

$\left(37^{\circ} \mathrm{C}\right) \mathrm{Sm}$ concentration in mixed biofilm $=10^{8}$ bacteria $/ \mathrm{mL}$
Fig 2: Mixed biofilms thicknesses and Af phenotype depending of $\mathrm{Sm}$ strains used $\left(37^{\circ} \mathrm{C}\right)$

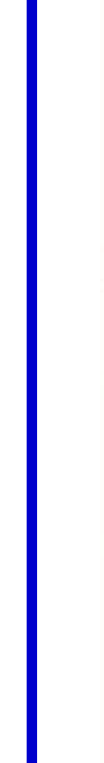

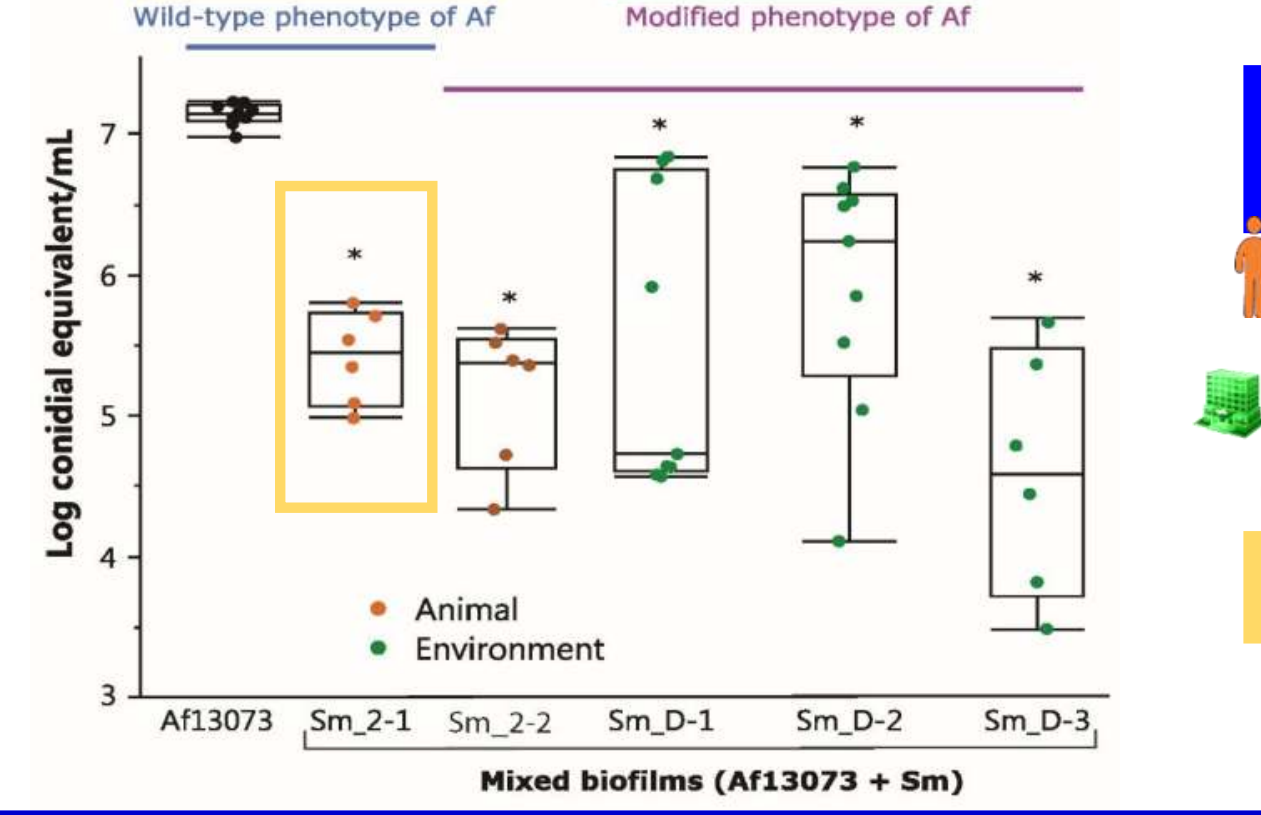

\begin{tabular}{|c|c|c|c|c|} 
Strains & $\begin{array}{c}\text { Planktonic } \\
\text { growth }\end{array}$ & Biofilm growth & Inhibition of Af & $\begin{array}{c}\text { Af modified } \\
\text { phenotype }\end{array}$ \\
\hline $\begin{array}{l}\text { Genogroup 6 } \\
\text { Genogroup D + }\end{array}$ & $37^{\circ} \mathrm{C}$ & $37^{\circ} \mathrm{C}$ & $10^{6}$ bacteria $/ \mathrm{mL}$ & $10^{6}$ bacteria $/ \mathrm{mL}$ \\
\hline Sm_2-2 & $25^{\circ} \mathrm{C}$ & $25^{\circ} \mathrm{C}$ & $10^{8}$ bacteria $/ \mathrm{mL}$ & $10^{8}$ bacteria $/ \mathrm{mL}$ \\
\hline Sm_2-1 & $25^{\circ} \mathrm{C}$ & $37^{\circ} \mathrm{C}$ & $10^{8}$ bacteria $/ \mathrm{mL}$ & no
\end{tabular}

The antibiosis effect observed in our previous study between two human clinical strains of $A$. fumigatus and S. maltophilia seems dependent of bacterial strains. The difference of bacterial effect on fungi is dose-dependant and directly related to the fitness of the bacterial strains at $37^{\circ} \mathrm{C}$. This effect is also dependent of other unknown factors, because Sm_2-1 doesn't induce any phenotype modification even with high concentration of bacteria (high growth at $37^{\circ} \mathrm{C}$ in biofilm condition). In further study, we will look for the molecules responsible of the antibiosis effects. 